\title{
ANALISIS KEPUASAN KONSUMEN HOTEL BINTANG 2 DAN BINTANG 5 DI SURABAYA: PENERAPAN PROSES TEXT-MINING ATAS ULASAN DARING KONSUMEN
}

\author{
Margaretha Felicia Thung $^{1 *}$, Bernadette Thalia Tjahjowidodo $^{1 *}$, Serli Wijaya ${ }^{1}$ \\ ${ }^{1}$ Program Studi Manajemen Perhotelan, Fakultas Bisnis dan Ekonomi Ekonomi, Universitas Kristen Petra \\ Jl. Siwalankerto 121-131, Surabaya 60236 \\ *Penulis korespondensi; Email: d11170290@john.petra.ac.id; d11170342@john.petra.ac.id
}

\begin{abstract}
Abstrak: Dengan berkembangnya teknologi, situs web berisi ulasan daring (online review website) sangat terkenal di kalangan konsumen karena ulasan daring dianggap sebagai sumber yang handal, terpercaya dan terbaru. Penelitian ini dilakukan untuk menganalisa ulasan daring di situs web Trip Advisor dan mengetahui atribut-atribut hotel yang menjadi penentu kepuasan maupun ketidakpuasan konsumen setelah menginap di hotel bintang 2 dan bintang 5 di Surabaya. Ulasan daring dianalisa melalui proses penambangan data (text-mining) menggunakan Voyant Tools. Hasil penelitian menunjukkan terdapat tujuh atribut hotel yaitu: Hotel, Service, Room, Food \& Beverage, Location, Security dan Price/value yang sama-sama menentukan kepuasan konsumen ketika menginap di hotel bintang 2 dan bintang 5. Sebaliknya terdapat enam atribut hotel yang menentukan ketidakpuasan konsumen setelah menginap di hotel bintang 5 yaitu: Room, Hotel, Service, Food \& Beverage, Location dan Price/value. Di sisi lain, atribut hotel yang paling banyak menjadi penyebab ketidakpuasan konsumen pada hotel bintang 2 adalah: Room, Hotel, Service, Food \& Beverage dan Price/value.
\end{abstract}

Kata kunci: Ulasan daring; text-mining; atribut hotel; kepuasan dan ketidakpuasan.

\begin{abstract}
Technology advancement has driven the increased popularity of online review websites since they are considered as reliable, trusted and up-to-date information source prior to consumer purchase decision. This study aimed to analyze online reviews and determine which hotel attributes that lead to consumer satisfaction and dissatisfaction both at 2 and 5 star hotels in Surabaya. Online reviews in this study were analyzed utilising Voyant, a text-mining tools. The results showed that there are seven hotel attributes that determine customer satisfaction after staying at 2-star and 5-star hotels, namely: Hotel, Service, Room, Food \& Beverage, Location, Security and Price/value. By contrast, there are six attributes that determine dissatisfaction at 5 star hotels are: Room, Hotel, Service, Food \& Beverage, Location and Price/value. Hotel attributes that lead to dissatisfaction with 2-star hotels are: Room, Hotel, Service, Food \& Beverage and Price / value.
\end{abstract}

Keywords: Online Review; text mining; hotel attributes; satisfaction and dissatisfaction.

\section{PENDAHULUAN}

Pada era modern ini teknologi berkembang sangat pesat dan salah satu bentuk berkembangnya teknologi adalah terciptanya berbagai macam media sosial. Dengan adanya perkembangan teknologi ini juga membuat konsumen semakin lebih terbuka dalam memberikan pendapat mengenai pengalaman yang dirasakan setelah mengkonsumsi sebuah jasa/produk di media sosial. Dari berbagai macam media sosial yang ada, situs web ulasan daring diakui sebagai salah satu alat yang paling mudah diakses untuk memahami pengalaman konsumen dengan lebih baik dan tepat (Pantelidis, 2010), contoh beberapa situs web ulasan daring yang sering digunakan yaitu TripAdvisor, Booking.com, Ctrip, dan lain-lain. Dari situs-situs web ulasan daring tersebut dapat menghasilkan electronic word of mouth (e-WOM) yang mempengaruhi keputusan pembelian potensial konsumen (Xu, 2018). Definisi dari e-WOM merupakan sebuah evaluasi produk yang dibuat oleh konsumen yang kemudian diposting di situs web perusahaan atau pihak ketiga.
Informasi yang didapatkan melalui e-WOM tidak hanya mengenai produk atau jasa saja, tetapi juga pada aspek pengalaman yang dirasakan oleh konsumen setelah mengkonsumsi produk maupun jasa seperti kualitas, value for money dan evaluasi secara keseluruhan (Li, Ye \& Law, 2013). Selain itu, dengan adanya ulasan daring ini merupakan salah satu sumber informasi untuk dapat mengetahui tingkat kepuasaan para konsumen, dimana jika para konsumen memberikan ulasan yang positif dapat diasumsikan bahwa konsumen merasa puas begitu juga dengan sebaliknya jika konsumen memberikan ulasan yang negatif dapat diasumsikan bahwa konsumen merasa tidak puas (Xu, 2018).

Dengan adanya situs web ulasan daring seperti sekarang ini tentunya mempengaruhi keputusan pembelian dari para calon konsumen, terlebih lagi jika terdapat ulasan negatif pada perusahaan yang dinilai. Menurut Berezina, Bilgihan, Cobanoglu dan Okumus (2016), ulasan negatif dapat menimbulkan kerugian bagi perusahaan apabila pada ulasan negatif tersebut mengandung kritikan yang terlalu ekstrim karena 
dapat menghalangi para calon konsumen untuk mempertimbangkan dalam memilih suatu produk atau merek tertentu. Selain itu, ulasan negatif juga dapat merusak reputasi perusahaan dan mengurangi penjualan serta dalam kasus ekstrim bisa menyebabkan kebangkrutan. Namun demikian, terdapat konsumen yang justru cenderung mencari ulasan negatif karena informasi pada ulasan negatif dianggap lebih mudah ditelaah dan informatif daripada ulasan positif atau ulasan netral. Selain membantu konsumen dalam mencari informasi sebelum pembelian, ulasan daring juga dapat membantu pihak manajemen untuk mengetahui kelebihan dan kekurangan dalam melayani konsumen, serta juga dapat menjadi sumber referensi yang bermanfaat cukup besar ketika ingin mempelajari dan memahami para konsumen. Atas dasar manfaat bagi kedua pihak inilah, penelitian untuk mengetahui atribut-atribut yang menjadi penentu kepuasan konsumen menjadi penting untuk dilakukan.

Di sisi lainnya, kumpulan data dari ulasan daring bertumbuh sangat cepat dan sangat kompleks sehingga membutuhkan teknik analisis khusus, infrastruktur teknologi, dan alat untuk mengolah data yang disebut big data atau "data besar" (Mirzaalian \& Halpenny, 2019). Oleh karena itu, diperlukan sebuah metode yang otomatis untuk menganalisis data dari ulasan daring seperti text mining tools. Text mining sendiri bertujuan untuk mengekstraksi informasi yang bermakna dari sejumlah besar dokumen/data tekstual yang tidak terstruktur dengan cepat serta lebih difokuskan pada menemukan model, trend, pengetahuan, pola, atau aturan yang berguna dan bermanfaat dari data tersebut (He et al., 2017). Hasil dari text mining tersebut berupa unsur kata-kata yang kemudian dikelompokkan berdasarkan frekuensi. Hasil dari pengelompokkan unsur kata-kata tersebut dinamakan sebagai word cloud yang digunakan untuk mengetahui atribut-atribut apa saja yang menjadi penentu kepuasan dan ketidakpuasan konsumen (He et al., 2017).

Berdasarkan jurnal penelitian Kim, Kim dan Heo (2016), hotel diklasifikasikan menjadi 2 kategori, yaitu full-service hotel dan limited-service hotel dimana yang termasuk dalam limited-service hotel yaitu hotel yang berbintang 1 dan 2 , serta yang termasuk dalam full-service hotel yaitu hotel bintang 4 dan 5. Hotel bintang 3 dianggap tidak termasuk dalam 2 klasifikasi hotel tersebut karena hotel bintang 3 tidak dapat diklasifikasikan dengan jelas apakah termasuk dalam full-service hotel atau limited-service hotel. Setiap kelas hotel akan memberikan layanan dan fasilitas yang berbeda sesuai dengan standar dan bintang hotel masing-masing. Maka dari itu dengan perbedaan layanan yang diberikan oleh hotel cenderung menyebabkan tingkat harapan para konsumen yang menginap berbeda-beda sesuai dengan bintang hotel yang dipilih (Kim, Kim \& Heo, 2016), sehingga atribut kepuasaan pada setiap kelas hotel pun berbeda-beda. Maka dari itu penelitian ini bertujuan untuk mengetahui atribut-atribut hotel yang menentukan kepuasan konsumen pada full-service hotel yang diwakilkan oleh hotel berbintang 5 dan limited-service hotel yang diwakilkan oleh hotel berbintang 2 dengan pendekatan text-mining. Dalam penelitian ini penulis akan mengambil ulasan daring yang berasal dari Tripadvisor.com karena karena TripAdvisor merupakan salah satu situs web ulasan daring dan platform pertukaran informasi yang terbesar di dunia, dimana TripAdvisor membantu 463 juta wisatawan di seluruh dunia untuk menelusuri lebih dari 859 juta ulasan (TripAdvisor, 2017; Liu, Liu, Mo \& Ng, 2020).

\section{LANDASAN TEORI}

\section{Limited-service hotel dan full-service hotel}

Hotel adalah sebuah tempat usaha yang menyediakan penginapan yang dibayar dalam jangka pendek (Walker, 2017). Dalam hal pengklasifikasian hotel, beberapa ahli juga sudah berusaha menetapkan standar industri yang telah diterima secara luas untuk mengklasifikasikan hotel berdasarkan jenisnya. Menurut Barrows, Powers dan Reynolds (2012) klasifikasikan hotel dapat dibagi menjadi 5 kategori yaitu : klasifikasi hotel berdasarkan harga (Limited-service hotels, Select-service hotels, Full-service hotels dan Luxury hotel), klasifikasi hotel berdasarkan fungsi (Convention hotels dan Commercial hotels), klasifikasi hotel berdasarkan lokasi (Downtown hotels, Suburban hotels, Highway/interstate hotels dan Airport hotels), klasifikasi hotel berdasarkan segmen pasar (Executive conference centers, Resorts, Casino hotels, Health spas dan Vacation ownership), klasifikasi hotel lainnya (All-suite hotels, Extended-stay hotels, Historic conversions, Bed-and-breakfast inns dan Boutique hotels). Kemudian pengertian dari Full-service hotels itu sendiri merupakan hotel yang menyediakan layanan lengkap dan menawarkan berbagai fasilitas kelas atas dengan volume besar, memiliki akomodasi yang lengkap serta restoran dengan layanan yang lengkap. Disisi lain Limited-service hotels biasanya hanya menawarkan fasilitas dengan jumlah yang sangat terbatas serta akomodasi dasar saja seperti kamar tamu. Jenis hotel ini biasanya hanya terdapat sedikit atau tidak ada ruang publik, tidak ada ruang meeting, dan fasilitas makanan dan minuman yang sangat terbatas (Barrows, Powers \& Reynolds, 2012; Walker, 2017). 


\section{Atribut Hotel}

Pada saat menginap disebuah hotel, tentunya atribut-atribut pada hotel tersebut sangat berpengaruh terhadap keputusan pembelian dari konsumen karena sebelum membuat keputusan pembelian, konsumen akan mempertimbangkan berbagai atribut pada hotel tersebut. Berikut ini adalah beberapa contoh atribut pada hotel yang berdasarkan penelitian penelitian terdahulu, menurut Berezina, Bilgihan, Cobanoglu dan Okumus (2016) terdapat 9 atribut pada hotel yang menentukan kepuasan konsumen yaitu Place of Business, Room, Members, Sport, Furnishing, Food and Table, Architecture, Family Structure dan Human Resource. Kemudian menurut Dong, Li dan Zhang (2014) mengklasifikasikan 7 atribut yang menjadi penentu kepuasan konsumen terdiri dari Hotel, Location, Room, Service, Dining \& Food, Value dan Facilities abilites. Berikutnya menurut Dolnicar dan Otter (2003) mengklasifikasikan atribut penentu kepuasan pada hotel menjadi 10 atribut yaitu Image, Price/Value, Hotel, Room, Services, Marketing, F\&B, Security, Location dan Others. Li, Ye dan Law (2013) juga mengklasifikasikan atribut penentu kepuasan pada hotel menjadi 6 atribut yaitu Logistics, Facilities, Reception Services, Food and Beverage management, Cleanliness and Management dan Value for money. Terakhir menurut Zhou, Ye, Pearce dan Wu (2014) atribut penentu kepuasan pada hoetel di bagi menjadi 6 atribut yang terdiri dari Room, Hotel, Food, Value, Location dan Staff.

\section{Kepuasan Konsumen}

Definisi kepuasan konsumen sudah banyak dikemukakan oleh beberapa ahli seperti Kotler dan Keller (2016) mengemukakan pengertian dari kepuasan konsumen yaitu perasaan senang atau kecewa seseorang yang dihasilkan dari membandingkan kinerja yang dirasakan (atau hasil) produk atau layanan dengan ekspektasi. Ketika konsumen mendapatkan suatu layanan, maka konsumen akan membandingkan layanan tersebut dengan ekspektasi yang diharapkan. Konsumen akan merasa puas apabila layanan yang diberikan memenuhi / melebihi harapannya. Namun, apabila layanan yang diberikan tidak memenuhi harapan dari konsumen, maka konsumen akan merasa tidak puas dengan layanan tersebut.

Seperti yang telah dipaparkan oleh Kotler dan Keller (2016) ekspektasi konsumen berpengaruh terhadap kepuasan konsumen. Dalam konteks manajemen hotel, ekspektasi konsumen dirumuskan secara berbeda tergantung pada kelas hotel. Pada setiap kelas hotel memberikan layanan dan fasilitas di tingkat kualitas tertentu. Dengan perbedaan tingkat pelayanan setiap hotel maka cenderung menimbulkan beragamnya tingkat harapan konsumen. Dengan demikian, layak bagi konsumen untuk memiliki tingkat ekspektasi yang berbeda dari setiap tingkatan kelas hotel yang berbeda (Kim, Kim dan Heo, 2016).

\section{Situs Web Ulasan Daring}

Situs web ulasan daring dapat dikategorikan menjadi 3, yaitu : OTA (Online Travel Agent), situs web hotel dan situs web ulasan daring (Belarmino \& Koh, 2018). Situs web ulasan daring seperti Trip Advisor sering kali menjadi situs web pilihan saat konsumen merencanakan perjalanannya. Para konsumen menjadi lebih percaya terhadap ulasan konsumen pada situs web ulasan daring dikarenakan para konsumen tersebut tidak berpihak pada hotel dalam memberikan ulasan, karena konsumen mengunggah ulasan berdasarkan pengalaman yang telah dirasakan (Belarmino \& Koh, 2018).

\section{Text Mining}

Text mining memiliki cakupan yang luas dan umumnya bertujuan untuk mengurai data tekstual untuk mengekstrak fakta yang dapat dibaca oleh perangkat elektronik (Mirzaalian \& Halpenny, 2019). Pada penelitian kali ini penulis menggunakan Voyant Tools sebagai alat untuk melakukan text mining. Menurut Sinclair dan Rockwell (2015), Voyant Tools adalah sebuah web basis yang terbuka untuk umum yang digunakan untuk membaca dan analisis teks yang menggunakan lebih dari 20 alat visualisasi untuk menganalisis korpus teks, yang memungkinkan pengguna untuk menyelidiki pola kata/konsep dan untuk mengeksplorasi dan memvisualisasikan korpus teks yang besar secara sistematis.

\section{METODE PENELITIAN}

\section{Populasi}

Menurut Sugiyono (2012) populasi merupakan wilayah generalisasi yang terdiri dari objek atau subjek yang mempunyai kualitas dan karakteristik tertentu yang ditetapkan oleh peneliti untuk dipelajari kemudian ditarik kesimpulannya. Jenis populasi yang ditentukan penulis dalam penelitian ini adalah ulasan daring berbahasa Inggris yang diunggah oleh para tamu yang menginap di hotel berbintang 2 dan bintang 5 di Surabaya pada TripAdvisor dengan jumlah ulasan daring sebesar 5.390.

\section{Sampel}

Menurut Sugiyono (2012) sampel adalah bagian dari jumlah dan karakteristik yang dimiliki oleh populasi tersebut. Dalam penelitian ini ulasan daring yang dianalisis adalah ulasan daring yang berbahasa Inggris yang diunggah oleh konsumen yang pernah menginap di hotel bintang 5 dan bintang 2 di Surabaya 
pada TripAdvisor yaitu dari bulan Januari tahun 2018 hingga bulan Desember tahun 2019. Kemudian ulasan daring yang diambil yaitu bernilai bintang 5 (Excellent) dan bernilai bintang 1 (Terrible).

\section{Variabel Penelitian}

Berdasarkan analisa literatur dari referensi yang diringkas dan dirangkum oleh penulis ditemukan 6 atribut-atribut pada hotel yang akan digunakan oleh penulis (Berezina, Bilgihan, Cobanoglu \& Okumus, 2016; Dong, Li \& Zhang, 2014; Li, Ye \& Law, 2013; Zhou, Ye, Pearce \& Wu, 2014 dan Dolnicar \& Otter, 2003). Variabel penelitian yang digunakan oleh penulis untuk menjawab masalah penelitian adalah sebagai berikut:

1. Hotel merupakan atribut yang berhubungan dengan hotel itu sendiri secara umum seperti hotel ambiance, hotel decoration, internet facilities, public facilities dan lain-lain.

2. Room merupakan atribut yang berhubungan dengan kamar hotel yang digunakan oleh konsumen seperti cleanliness of the room, amenities, room size and layout, toilet and bathroom dan lainlain.

3. Food \& Beverage merupakan atribut yang berhubungan dengan layanan makanan dan minuman yang ada di hotel seperti variety of food and beverage, quality of food and beverage, barl lounge, breakfast, lunch, dinner dan lain-lain.

4. Location merupakan atribut yang berhubungan dengan lokasi dari hotel itu sendiri seperti close to city center, convenient to tourist destination, close to the airport or railway station, convenient to downtown, transportation convenience dan lainlain.

5. Price/value merupakan atribut yang berhubungan dengan harga dibayarkan oleh konsumen serta nilai yang didapatkan seperti price of accommodation, value for money, food and beverage price, free parking dan lain-lain.

6. Service merupakan atribut yang berhubungan dengan layanan yang diberikan oleh hotel seperti friendliness and helpfulness of the staff, reservation handling, check in/check out, staff \& professionalism dan lain-lain.

\section{TEKNIK ANALISIS DATA}

\section{Analisis Statistik Deskriptif}

Pada penelitian ini penulis menggunakan tabel distribusi frekuensi untuk menggambarkan data dari hotel dan ulasan daring yang digunakan oleh penulis seperti nama hotel, bintang hotel, jumlah hotel serta jumlah ulasan negatif dan positif.

\section{Langkah-langkah Analisis Data}

Untuk meningkatkan keandalan dan validitas penelitian ini, pengumpulan dan analisis data mengikuti beberapa langkah:

\section{Persiapan}

Pada langkah pertama, untuk mengidentifikasi ulasan yang mengindikasikan kepuasan dan ketidakpuasan, penelitian ini merujuk pada pedoman TripAdvisor. Peringkat bintang yang wisatawan berikan di situs web TripAdvisor dirancang untuk menunjukkan evaluasi keseluruhan pengalaman menginap di hotel dari (1) "terrible" (2) "poor", (3) "average", (4) "very good" and (5) "excellent". Dalam penelitian ini, ulasan positif yang termasuk dalam kategori "excellent" dianalisis untuk mengidentifikasi atribut pemuas dan didefinisikan sebagai "ulasan yang menunjukkan kepuasan", sedangkan ulasan negatif dalam kategori "terrible" dianalisis untuk menyelidiki ketidakpuasan dan didefinisikan sebagai "ulasan yang menunjukkan ketidakpuasan".

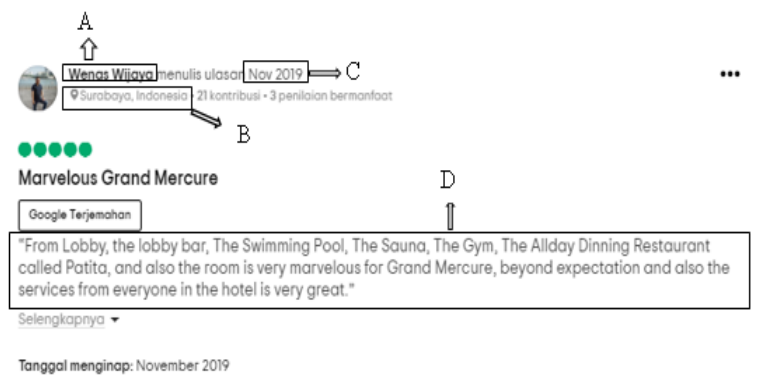

Gambar 1. Contoh Ulasan Daring pada TripAdvisor

Setelah penulis menemukan ulasan daring seperti contoh diatas.Kemudian ulasan daring tersebut dimasukkan kedalam tabel pada microsoft word. Informasi yang dikumpulkan ke dalam microsoft word seperti nama penulis ulasan daring (A), tempat asal(B), tanggal penulisan(C) serta ulasan daring itu sendiri(D) seperti pada Tabel 1.

Tabel 1. Langkah Pertama Reduksi Ulasan Daring

\begin{tabular}{|c|c|c|c|c|}
\hline Hotel. & No. & Profil Penulis & Ulasan Daring & $\begin{array}{l}\text { Ulasan Daring } \\
\text { Setelah Disaring }\end{array}$ \\
\hline $\begin{array}{l}\text { Grand } \\
\text { Mercure } \\
\text { Surabaya }\end{array}$ & 1. & $\begin{array}{l}\text { Nama } \\
W^{* * * * *} W^{* * * * * *}\end{array}$ & $\begin{array}{l}\text { From Lobby, the lobby bar, } \\
\text { The Swimming Pool, The } \\
\text { Sauna, The Gym, The Allday, }\end{array}$ & \\
\hline City & & $\begin{array}{l}\text { Tempat asal: } \\
\text { Surabaya } \\
\text { Indonesia } \\
\text { Tanggal penulisan: } \\
\text { November } 2019\end{array}$ & $\begin{array}{l}\text { Dinning Restaurant called } \\
\text { Patita, and also the room is } \\
\text { very marvelous for Grand } \\
\text { Mercure, beyond expectation } \\
\text { and also the services from } \\
\text { everyone in the hotel is very } \\
\text { great. }\end{array}$ & \\
\hline
\end{tabular}

Pada tahap ini terdapat 10 hotel bintang 5 dan 17 hotel bintang 2 di Surabaya yang akan digunakan ulasan daringnya. 


\section{Pembuatan Corpus}

Pada tahap kedua, setelah penulis mengumpulkan semua ulasan daring yang digunakan ke dalam microsoft word, penulis menemukan bahwa dari 17 hotel bintang 2 hanya terdapat 8 hotel dan pada hotel bintang 5 terdapat 10 hotel yang memiliki ulasan daring sesuai dengan kriteria penulis seperti ulasan harus berbahasa Inggris serta diunggah pada bulan Januari 2018 - Desember 2019. Kemudian ulasan daring tersebut disaring oleh penulis dengan cara menghilangkan ulasan yang berbentuk saran, masukan dan kata-kata yang tidak diperlukan seperti apabila pada ulasan daring negatif terdapat ulasan positif dan sebagainya agar data yang dianalisis benar-benar mengungkapkan kepuasan dan ketidakpuasan konsumen, seperti di bawah ini:

Tabel 2. Langkah Pertama Reduksi Ulasan Daring

\begin{tabular}{lclll}
\hline \multicolumn{1}{c}{ Hotel. } & No. & \multicolumn{1}{c}{ Frofil Penulis } & \multicolumn{1}{c}{ Ulasan Daring } & \multicolumn{1}{c}{ Ulasan Daring Setelah } \\
Disaring
\end{tabular}

Setelah semua file sudah terkumpulkan dan sudah disaring, kemudian penulis membuat file baru yang hanya berisi ulasan daring positif maupun negatif pada setiap hotel setelah disaring untuk kemudian digunakan pada proses text-mining dengan menggunakan Voyant Tools.

\section{Proses Text-Mining menggunakan Voyant Tools}

Pada penelitian ini, proses text-mining dilakukan dengan menggunakan Voyant Tools. Setelah selesai membuat corpus kemudian corpus tersebut diunggah pada Voyant Tools, berikut ini adalah tampilan dari situs web Voyant Tools:
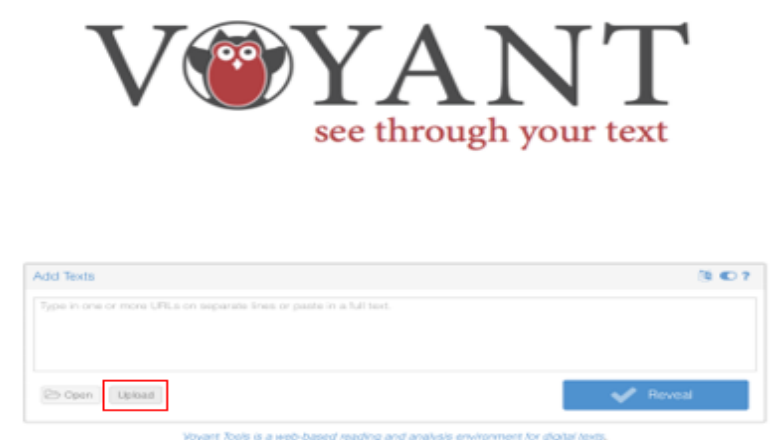

Gambar 2. Tampilan Situs Web Voyant Tools
Pada penelitian ini hasil dari Voyant Tools yang digunakan adalah word cloud, reader dan summary (most frequent words), dibawah ini adalah contoh hasil dari Voyant Tools:

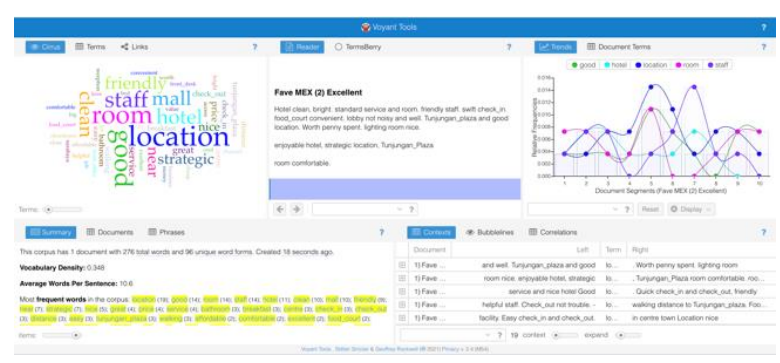

Gambar 3. Tampilan Hasil Analisis Voyant Tools

\section{HASIL DAN PEMBAHASAN}

Dari data ulasan daring berbahasa Inggris bernilai 5 (excellent) dan bernilai 1 (terrible), yang diunggah pada Januari 2018 - Desember 2019 di situs web TripAdvisor pada hotel bintang 5 dan bintang 2 di Surabaya, diperoleh total data ulasan daring sebanyak 960 ulasan. Dari total ulasan daring tersebut, terdapat 30 ulasan daring yang tidak memenuhi syarat yang ditentukan oleh penulis yaitu ulasan harus berbahasa Inggris dan mengandung atribut kepuasan atau ketidakpuasan, sehingga 30 ulasan daring tersebut tidak digunakan oleh penulis. Maka total ulasan daring yang digunakan oleh penulis sebanyak 930 ulasan. Dari 930 ulasan daring, ulasan yang berasal dari hotel bintang 5 sebanyak 799 ulasan dan ulasan yang berasal dari hotel bintang 2 sebanyak 131 ulasan, dengan rincian ulasan daring positif dan negatif seperti pada Tabel 3.

Tabel 3. Data Ulasan Daring pada Hotel Bintang 5

\begin{tabular}{|c|c|c|c|c|c|c|}
\hline \multirow[t]{2}{*}{ No. } & \multirow[t]{2}{*}{ Nama Hotel } & \multirow[t]{2}{*}{ Bintang } & \multicolumn{2}{|c|}{$\begin{array}{l}\text { Jumlah ulasan } \\
\text { daring }\end{array}$} & \multicolumn{2}{|c|}{ Persentase } \\
\hline & & & Positif & Negatif & Positif & Negatif \\
\hline 1 & JW Marriott Hotel & 5 & 93 & 5 & $11.99 \%$ & $21.74 \%$ \\
\hline 2 & Shangri-La Hotel Surabaya & 5 & 97 & 2 & $12.5 \%$ & $8.70 \%$ \\
\hline 3 & Bumi Surabaya City Resort & 5 & 61 & 2 & $7.86 \%$ & $8.70 \%$ \\
\hline 4 & $\begin{array}{l}\text { Hotel Ciputra World } \\
\text { Surabaya }\end{array}$ & 5 & 139 & 2 & $17.91 \%$ & $8.70 \%$ \\
\hline 5 & Vasa Hotel Surabaya & 5 & 126 & 5 & $16.24 \%$ & $21,74 \%$ \\
\hline 6 & Grand Mercure Surabaya & 5 & 7 & 0 & $0.90 \%$ & - \\
\hline 7 & Wyndham Surabaya & 5 & 31 & 2 & $3.99 \%$ & $8.70 \%$ \\
\hline 8 & Hotel Majapahit Surabaya & 5 & 144 & 2 & $18.56 \%$ & $8.70 \%$ \\
\hline 9 & Oakwood Hotel \& Residence & 5 & 15 & 0 & $1.93 \%$ & - \\
\hline 10 & Sheraton Hotel \& Towers & 5 & 63 & 3 & $8.12 \%$ & $13,04 \%$ \\
\hline & Total Ulasan & & 776 & 23 & $100 \%$ & $100 \%$ \\
\hline
\end{tabular}

Tabel 4. Data Ulasan Daring pada Hotel Bintang 2

\begin{tabular}{crrrrrr}
\hline \multirow{2}{*}{ No. } & \multirow{2}{*}{ Nama Hotel } & \multirow{2}{*}{ Bintang } & \multicolumn{2}{c}{$\begin{array}{c}\text { Jumlah ulasan } \\
\text { daring }\end{array}$} & \multicolumn{2}{c}{ Persentase } \\
\cline { 4 - 7 } & & & Positif & Negatif & Positif & Negatif \\
\hline 1 & Hotel 88 Embong Malang & 2 & 3 & 0 & $2.4 \%$ & - \\
2 & Hotel 88 Embong Kenongo & 2 & 1 & 0 & $0.8 \%$ & - \\
3 & Amaris Hotel Margorejo & 2 & 1 & 0 & $0.8 \%$ & - \\
4 & Bella Hotel & 2 & 0 & 1 & - & $16.67 \%$ \\
5 & Favehotel MEX Surabaya & 2 & 26 & 1 & $20.8 \%$ & $16.67 \%$ \\
6 & POP! Hotel Gubeng & 2 & 81 & 3 & $64.8 \%$ & $50 \%$ \\
7 & POP! Hotel Diponegoro & 2 & 12 & 0 & $9.6 \%$ & - \\
8 & Hotel Sahid Surabaya & 2 & 1 & 1 & $0.8 \%$ & $16.67 \%$ \\
\hline \multicolumn{2}{r}{ Total Ulasan } & & $\mathbf{1 2 5}$ & $\mathbf{6}$ & $\mathbf{1 0 0} \%$ & $\mathbf{1 0 0 \%}$ \\
\hline
\end{tabular}




\section{Atribut Penentu Kepuasan pada Hotel Bintang 5 dan Bintang 2 di Surabaya}

Tabel 5. Hasil Rangkuman dari Frekuensi Kemunculan Atribut Penentu Kepuasan pada Hotel bintang 5 dan bintang 2 di Surabaya

\begin{tabular}{clrrrlrr}
\hline & \multicolumn{3}{c}{ Hotel Bintang 5 } & \multicolumn{5}{c}{ Hotel Bintang 2 } \\
\hline Peringkat & $\begin{array}{c}\text { Atribut } \\
\text { kepuasan }\end{array}$ & f & $(\%)$ & Peringkat & $\begin{array}{c}\text { Atribut } \\
\text { kepuasan }\end{array}$ & f & $(\%)$ \\
\hline 1 & Service & 926 & $25.84 \%$ & 1 & Service & 130 & $26.37 \%$ \\
2 & Hotel & 849 & $23.69 \%$ & 2 & Room & 116 & $23.53 \%$ \\
3 & Room & 799 & $22.29 \%$ & 3 & Hotel & 93 & $18.86 \%$ \\
4 & F\&B & 669 & $18.66 \%$ & 4 & Location & 70 & $14.2 \%$ \\
5 & Location & 268 & $7.48 \%$ & 5 & Price/value & 41 & $8.32 \%$ \\
6 & Price/value & 62 & $1.73 \%$ & 6 & F\&B & 40 & $8.11 \%$ \\
7 & Security & 11 & $0.31 \%$ & 7 & Security & 3 & $0.61 \%$ \\
\hline \multicolumn{2}{l}{ Total jumlah kata } & $\mathbf{3 , 5 8 4}$ & $\mathbf{1 0 0 \%}$ & Total jumlah kata & $\mathbf{4 9 3}$ & $\mathbf{1 0 0 \%}$ \\
\hline
\end{tabular}

Dari hasil ini dapat dilihat bahwa atribut-atribut penentu kepuasan konsumen baik pada hotel bintang 5 maupun hotel bintang 2 terdapat 7 atribut seperti yang terlihat pada tabel di atas. Atribut Service, Hotel, Room dan Food \& Beverage adalah atribut yang secara merata paling menentukan kepuasan konsumen pada hotel bintang 5. Total persentase dari keempat atribut ini adalah sebesar $90.48 \%$, sedangkan untuk atribut lainnya memiliki persentase yang sangat kecil dalam menentukan kepuasan. Atribut Service, Room, Hotel dan Location adalah atribut yang secara merata paling menentukan kepuasan konsumen pada hotel bintang 2 karena memiliki total persentase sebesar $82.96 \%$. Di sisi lain untuk atribut lainnya memiliki persentase yang sangat kecil dalam menentukan kepuasan konsumen pada hotel bintang 2 .

Pada tabel 5 dapat dilihat bahwa terdapat persamaan dari sisi peringkat pada atribut, atribut yang paling menentukan kepuasan konsumen baik pada hotel bintang 5 maupun hotel bintang 2 di Surabaya yaitu atribut Service. Atribut tersebut berada pada peringkat satu dengan persentase $25.84 \%$ di hotel bintang 5 dan $26.37 \%$ pada hotel bintang 2. Melalui data di atas dapat disimpulkan bahwa baik pada fullservice hotel yang diwakilkan oleh hotel bintang 5 maupun pada limited-service hotel yang diwakilkan oleh hotel bintang 2, atribut Service sangat menentukan kepuasan konsumen. Hal ini juga sesuai dengan studi literatur yang telah dilakukan oleh penulis, menurut Walker (2017) mengatakan bahwa industri perhotelan adalah usaha yang bergerak secara luas dalam industri jasa sehingga dapat dikatakan bahwa jasa pelayan pada hotel menjadi hal yang paling disorot oleh konsumen. Selain itu, ditemukan juga persamaan lainnya yaitu pada atribut Security dimana atribut ini sama-sama memiliki persentase yang paling kecil dalam menentukan kepuasan konsumen pada hotel bintang 5 maupun hotel bintang 2. Dari sisi atribut, pada hotel bintang 2 dan bintang 5 di Surabaya samasama memiliki 7 atribut penentu kepuasan yaitu Room, Hotel, Food \& Beverage, Service, Location, Pricel value dan Security.
Di sisi lain, terdapat juga perbedaan yang dapat ditemukan dari sisi peringkat pada atribut penentu kepuasan. Selain atribut Service dan Security yang memiliki kesamaan, atribut lainnya memiliki peringkat yang berbeda-beda dalam menentukan kepuasan konsumen. Sebagai contoh dapat dilihat pada tabel di atas bahwa atribut Food \& Beverage pada hotel bintang 5 termasuk kedalam salah satu atribut yang paling menentukan kepuasan konsumen, sedangkan pada hotel bintang 2 atribut Food \& Beverage termasuk kedalam salah satu atribut yang memiliki peranan yang kecil dalam menentukan kepuasan konsumen. Kemudian pada bagian selanjutnya, penulis akan menjelaskan mengenai detail dari atributatribut di atas.

Pada atribut Service, detail atribut yang paling menentukan kepuasan konsumen pada hotel bintang 2 dan bintang 5 adalah friendliness dan helpfulness of the staff. Kemudian pada atribut Hotel detail atribut yang paling menentukan kepuasan konsumen pada hotel bintang 5 adalah public facility sedangkan pada hotel bintang 2 adalah internet facility. Disisi lain pada atribut Room detail atribut yang paling menentukan kepuasan konsumen pada hotel bintang 5 adalah Room size and layout, sedangkan pada hotel bintang 2 adalah Cleanliness. Lalu pada detail atribut Food \& Beverage yang paling menentukan kepuasan konsumen hotel bintang 5 maupun hotel bintang 2 adalah breakfast. Hal ini juga terjadi pada atribut Location dimana detail atribut yang paling menentukan kepuasan konsumen bintang 2 dan bintang 5 di Surabaya adalah Convenience to tourist destination. Disisi lain pada atribut Price detail atribut yang paling menentukan kepuasan pada hotel bintang 2 dan bintang 5 di Surabaya ternyata memiliki persamaan yaitu mengenai price of accommodation. Untuk atribut terakhir yaitu atribut Security detail atribut yang paling menentukan kepuasan konsumen baik pada bintang 5 maupun bintang 2 adalah security of hotels.

\section{Atribut Penentu Ketidakpuasan pada Hotel Bintang 5 dan Bintang 2 di Surabaya}

Tabel 6. Hasil Rangkuman dari Frekuensi Kemunculan Atribut Penentu Ketidakpuasan pada Hotel bintang 5 dan bintang 2 di Surabaya

\begin{tabular}{clrrrlrr}
\hline \multicolumn{3}{c}{ Hotel Bintang 5 } & \multicolumn{5}{c}{ Hotel Bintang 2 } \\
\hline Peringkat & $\begin{array}{c}\text { Atribut } \\
\text { ketidakpuasan }\end{array}$ & $\mathrm{f}$ & $\mathbf{( \% )}$ & Peringkat & $\begin{array}{c}\text { Atribut } \\
\text { ketidakpuasan }\end{array}$ & $\mathrm{f}$ & (\%) \\
\hline 1 & Service & 24 & $30.77 \%$ & 1 & Room & 23 & $58.97 \%$ \\
2 & Room & 24 & $30.77 \%$ & 2 & F\&B & 6 & $15.39 \%$ \\
3 & Hotel & 20 & $25.64 \%$ & 3 & Hotel & 6 & $15.39 \%$ \\
4 & F\&B & 7 & $8.97 \%$ & 4 & Service & 3 & $7.69 \%$ \\
5 & Location & 2 & $2.56 \%$ & 5 & Price/value & 1 & $2.56 \%$ \\
6 & Price/value & 1 & $1.28 \%$ & 6 & Location & - & - \\
7 & Security & - & - & 7 & Security & - & - \\
\hline \multicolumn{2}{l}{ Total jumlah kata } & $\mathbf{7 8}$ & $\mathbf{1 0 0} \%$ & \multicolumn{7}{c}{ Total jumlah kata } & $\mathbf{3 9}$ & $\mathbf{1 0 0 \%}$ \\
\hline
\end{tabular}


Dari hasil ini dapat dilihat bahwa terdapat 6 atribut penentu ketidakpuasan konsumen pada hotel bintang 5 dan pada hotel bintang 2 terdapat 5 atribut penentu ketidakpuasan. Atribut Room, Service dan Hotel adalah atribut yang secara merata paling menentukan ketidakpuasan konsumen pada hotel bintang 5. Total persentase dari ketiga atribut ini adalah sebesar $87.18 \%$, sedangkan untuk atribut lainnya memiliki persentase yang sangat kecil dalam menentukan ketidakpuasan. Atribut Room, Food \& Beverage dan Hotel adalah atribut yang secara merata paling menentukan ketidakpuasan konsumen pada hotel bintang 2 karena memiliki total persentase sebesar $89.75 \%$. Pada atribut penentu ketidakpuasan hotel bintang 5 dan hotel bintang 2 tidak terdapat atribut Security. Atribut ini tidak terdapat pada ketidakpuasan dikarenakan menurut penulis atribut Security ini tidak menjadi prioritas konsumen pada saat menginap di hotel. Hal ini terjadi karena para konsumen sudah mengetahui bahwa keamanan di hotel itu sangat terjamin, seperti terdapat satpam yang selalu ada di depan hotel, terdapat Standard Operasional Procedure keamanan pada setiap hotel dan lain-lain, maka dari itu tidak terdapat atribut Security pada ketidakpuasan konsumen.

Dari hasil pada tabel 6 dapat dilihat bahwa terdapat beberapa kesamaan pada atribut ketidakpuasan hotel bintang 5 dan bintang 2 . Dari sisi persentase atribut, pada tabel atribut penentu ketidakpuasan konsumen hotel bintang 5 terdapat 2 atribut yang memiliki persentase yang sama yaitu atribut Service dan Room, sehingga kedua atribut ini memiliki peran yang sama besar dalam menentukan ketidakpuasan konsumen. Sedangkan pada hotel bintang 2 yang juga memiliki kesamaan persentase yaitu atribut Food \& Beverage dan Hotel. Sehingga dapat dikatakan kedua atribut tersebut memiliki peran yang sama besar dalam menentukan ketidakpuasan konsumen. Selain itu dari sisi peringkat, dapat dilihat juga bahwa atribut Price/value baik pada ketidakpuasan hotel bintang 5 maupun bintang 2 sama-sama memiliki persentase yang paling kecil dalam menentukan ketidakpuasan. Dari sisi atribut, atribut pada hotel yang sama-sama menjadi penentu ketidakpuasan konsumen hotel bintang 2 dan bintang 5 di Surabaya yaitu Hotel, Room, Service, Food \& Beverage dan Price/value.

Sebaliknya, terdapat juga perbedaan pada tabel di atas. Perbedaan pertama yang dapat dilihat adalah pada atribut Location dimana atribut ini hanya terdapat pada hotel bintang 5 sedangkan pada hotel bintang 2 tidak ditemukan. Hal ini merupakan suatu penemuan yang menarik bagi penulis karena pada saat penulis akan menjelaskan lebih detail mengenai atribut ketidakpuasan Location, penulis menemukan bahwa hal ini hanya terjadi pada Vasa Hotel Surabaya karena lokasi yang terletak agak jauh dari pusat perbelanjaan dan tengah kota. Fenomena ini menjadi menarik karena pada ketentuan yang di berikan oleh PHRI maupun pemerintah, lokasi yang dekat dengan mall maupun tengah kota bukan merupakan kriteria penentu sebuah hotel menjadi bintang 5, namun di sisi lain konsumen hotel bintang 5 di Surabaya memperhatikan atribut Location dan atribut ini dapat menentukan kepuasan konsumen. Perbedaan berikutnya dapat dilihat dari sisi peringkat dimana pada hotel bintang 5 atribut Service berada di peringkat pertama sebagai atribut penentu ketidakpuasan konsumen. Hal ini sesuai dengan yang dikatakan oleh Kim, Kim dan Heo (2016) bahwa konsumen hotel mewah mengharapkan layanan berkualitas tinggi dan suasana mewah sehingga wajar bahwa atribut Service berada pada peringkat pertama karena konsumen pada hotel bintang 5 tentunya mengharapkan untuk mendapatkan layanan dengan kualitas yang tinggi. Dapat dilihat pula, pada atribut penentu ketidakpuasan hotel bintang 2 bahwa atribut Room berada pada peringkat pertama dengan persentase lebih dari 50\%, melalui data ini maka dapat dikatakan bahwa dari seluruh ulasan daring ketidakpuasan pada hotel bintang 2, setengah dari ulasan tersebut selalu memberikan ulasan tidak puas mengenai Room. Hal ini juga sesuai dengan studi literatur yang telah dilakukan oleh penulis bahwa menurut Barrows, Powers dan Reynolds, (2012) serta Walker, (2017) limited-service hotels biasanya hanya menawarkan fasilitas dengan jumlah yang sangat terbatas serta akomodasi dasar saja seperti kamar tamu. Sehingga pada hotel bintang 2 hal yang paling disoroti oleh konsumen yaitu kamar dari hotel tersebut. Kemudian pada bagian selanjutnya, penulis akan menjelaskan mengenai detail dari atribut-atribut di atas yang telah diperoleh.

Pada atribut penentu ketidakpuasan Room detail atribut yang paling menentukan pada hotel bintang 5 adalah bathroom sedangkan pada hotel bintang 2 adalah cleanliness. Kemudian pada atribut Service detail atribut yang paling menentukan ketidakpuasan konsumen pada hotel bintang 5 adalah Staff and professionalism, sedangkan detail atribut Service yang paling menentukan ketidakpuasan pada hotel bintang 2 yaitu Service quality. Selanjutnya pada atribut Hotel, detail atribut yang paling menentukan ketidakpuasan pada hotel bintang 5 yaitu public facility (lobby) dan internet facility, sedangkan detail atribut Hotel yang paling menentukan ketidakpuasan pada hotel bintang 2 yaitu internet facility. Disisi lain pada atribut Food \& Beverage detail atribut yang menentukan kepuasan konsumen pada hotel bintang 5 adalah $F \& B$ quality, sedangkan pada hotel bintang 2 adalah $F \& B$ quality 
dan Breakfast. Kemudian pada atribut Location yang hanya terdapat pada hotel bintang 5 , detail atribut yang menjadi penentu ketidakpuasan adalah lokasi yang kurang strategis. Pada atribut Price/value penulis tidak bisa menyimpulkan detail atribut apa yang paling menentukan ketidakpuasan pada konsumen bintang 5 maupun bintang 2 karena pada masing-masing hotel hanya ditemukan satu ulasan daring saja mengenai atribut Price/value.

\section{KESIMPULAN DAN SARAN}

\section{Kesimpulan}

Berdasarkan hasil analisa dan pembahasan yang telah dilakukan oleh penulis maka dapat ditarik kesimpulan bahwa terdapat 7 atribut penentu kepuasan konsumen pada hotel bintang 2 dan bintang 5 di Surabaya yaitu Hotel, Room, Service, Food \& Beverage, Location, Price/value dan Security dan ke 7 atribut tersebut sama-sama menjadi atribut penentu kepuasan konsumen pada hotel bintang 2 dan bintang 5 di Surabaya. Kemudian terdapat 5 atribut penentu ketidakpuasan konsumen pada hotel bintang 2 di Surabaya yaitu Hotel, Room, Service, Food \& Beverage, dan Price/value. Disamping itu atribut penentu ketidakpuasan pada hotel bintang 5 di Surabaya terdapat 6 atribut yaitu Hotel, Room, Service, Food \& Beverage, Location dan Price/value. Terdapat persamaan dari atribut-atribut penentu ketidakpuasan konsumen pada hotel bintang 2 dan bintang 5 di Surabaya yaitu terdapat 5 atribut yang terdiri dari Hotel, Room, Service, Food \& Beverage dan Pricel value. Selain persamaan, terdapat juga perbedaan dari atribut-atribut penentu ketidakpuasan pada hotel bintang 2 dan bintang 5 di Surabaya yaitu pada atribut Location karena atribut ini hanya terdapat pada hotel bintang 5 di Surabaya.

\section{Saran}

Bagi Pihak Hotel Bintang 2 di Surabaya penulis menemukan bahwa pada Hotel Bintang 2 atribut Service berada pada peringkat satu dalam menjadi penentu kepuasan konsumen. Kemudian penulis juga menemukan bahwa friendliness and helpfulness of the staff merupakan bagian dari atribut Service yang paling dominan dalam menentukan kepuasan konsumen. Maka dari itu penulis menyarankan agar Hotel Bintang 2 dapat terus mempertahankan dan meningkatkan keramahan dari staf yang dimiliki.

Namun disisi lain penulis juga menemukan bahwa atribut Room berada pada peringkat pertama untuk ketidakpuasan konsumen pada Hotel Bintang 2 dimana detail atribut yang paling menentukan ketidakpuasan pada Hotel Bintang 2 adalah cleanliness. Berdasarkan hasil yang ditemukan, maka dari itu penulis menyarankan bagi Hotel Bintang 2 agar lebih memperhatikan dan memperbaiki kebersihan kamarnya dengan selalu membersihkan kamar dan melakukan pengecekan ulang pada kamar sebelum konsumen menginap.

Bagi Pihak Hotel Bintang 5 di Surabaya penulis menemukan bahwa pada Hotel Bintang 5 atribut Service berada pada peringkat satu dalam menjadi penentu kepuasan konsumen. Kemudian penulis juga menemukan bahwa friendliness and helpfulness of the staff merupakan bagian dari atribut Service yang paling dominan dalam menentukan kepuasan konsumen. Oleh karena itu, penulis menyarankan agar Hotel Bintang 5 dapat terus mempertahankan dan meningkatkan keramahan dari staf yang dimiliki.

Namun disisi lain, penulis menemukan bahwa atribut Service merupakan salah satu atribut yang paling dominan dalam menentukan ketidakpuasan konsumen pada Hotel Bintang 5 dimana detail atribut yang paling dominan adalah professionalism of the staff. Maka dari itu, tidak hanya memperhatikan keramahtamahan dari staf saja, tetapi juga perlu untuk memperbaiki dan meningkatkan lagi professionalism of the staff seperti memberikan evaluasi secara berkala berdasarkan dari ulasan-ulasan daring yang tidak puas dari para konsumen serta pelatihan secara berkala mengenai standard operasional procedure dalam melayani konsumen agar profesionalitas dari para staf tetap terjaga. Kemudian penulis menemukan bahwa atribut Room juga merupakan salah satu atribut yang paling dominan dalam menjadi penentu ketidakpuasan konsumen pada Hotel Bintang 5, dimana detail atribut yang paling menentukan ketidakpuasan pada Hotel Bintang 5 adalah air pada bathroom. Maka dari itu penulis menyarankan pada hotel bintang 5 agar dapat melakukan pengecekan berkala terhadap air kamar mandi pada hotel tersebut.

Bagi Industri Perhotelan. Berdasarkan hasil dari penelitian yang dilakukan oleh penulis, isi dari ulasan daring merupakan salah satu sumber untuk mengetahui pendapat konsumen mengenai pengalaman yang dirasakan ketika menginap pada hotel. Maka dari itu pihak hotel perlu untuk memperhatikan ulasan-ulasan daring terutama ulasan daring yang bernada negatif agar dapat segera diperbaiki dan ditingkatkan.

\section{DAFTAR PUSTAKA}

Barrows, C.W., Powers, T. \& Reynolds, D. (2012). Introduction to Management in The Hospitality Industry (10th ed.). Hoboken, NJ: John Wiley \& Sons, Inc. 
Belarmino, A. M., \& Koh, Y. (2018). How E-WOM motivations vary by hotel review website. International Journal of Contemporary Hospitality Management, 30(8), 2730-2751. https://doi. org/10.1108/JCHM-02-2017-0055

Berezina, K., Bilgihan, A., Cobanoglu, C., \& Okumus, F. (2016). Understanding satisfied and dissatisfied hotel customers: Text mining of online hotel reviews. Journal of Hospitality Marketing and Management, 25(1), 1-24. https://doi.org/10. 1080/19368623.2015.983631

Dolnicar, S., \& Otter, T. (2003). Which hotel attributes matter? A review of previous and a framework for future research. Proceedings of the 9th Annual Conference of the Asia Pacific Tourism Association (APTA), 1, 176-188. https://doi.org/10. 1002/9781444317619.ch24

Dong, J., Li, H., \& Zhang, X. (2014). Classification of customer satisfaction attributes: An application of online hotel review analysis. IFIP Advances in Information and Communication Technology, 445(2008), 238-250. https://doi.org/10.1007/97 8-3-662-45526-5_23

He, W., Tian, X., Tao, R., Zhang, W., Yan, G., \& Akula, V. (2017). Application of social media analytics: a case of analyzing online hotel reviews. Online Information Review, 41(7), 921935. https://doi.org/10.1108/oir-05-2014-002

Kim, B., Kim, S., \& Heo, C. Y. (2016). Analysis of satisfiers and dissatisfiers in online hotel reviews on social media. International Journal of Contemporary Hospitality Management, 28(9), 1915-1936. https://doi.org/10.1108/IJCHM-042015-0177

Kotler, P., and Keller, K. L. (2016). Marketing Management (15th ed.). Harlow: Pearson Education Limited.

Li, H., Ye, Q., \& Law, R. (2013). Determinants of customer satisfaction in the hotel industry: An application of online review analysis. Asia Pacific Journal of Tourism Research, 18(7), 784-802. https://doi.org/10.1080/10941665.2012.708351

Li, H., Ye, Q., \& Law, R. (2013). Determinants of customer satisfaction in the hotel industry:
An application of online review analysis. Asia Pacific Journal of Tourism Research, 18(7), 784 802. https://doi.org/10.1080/10941665.2012. 708351

Liu, M. T., Liu, Y., Mo, Z., \& Ng, K. L. (2020). Using text mining to track changes in travel destination image: The case of macau. Asia Pacific Journal of Marketing and Logistics. https://doi.org/ 10.1108/APJML-08-2019-0477

Mirzaalian, F., \& Halpenny, E. (2019). Social media analytics in hospitality and tourism and future trends. Journal of Hospitality and Tourism Technology, 10(4), 764-790. https://doi.org/ 10.1108/JHTT-08-2018-0078

Mirzaalian, F., \& Halpenny, E. (2019). Social media analytics in hospitality and tourism and future trends. Journal of Hospitality and Tourism Technology, 10(4), 764-790. https://doi.org/10.1108/ JHTT-08-2018-0078

Pantelidis, I. S. (2010). Electronic meal experience: A content analysis of online restaurant comments. Cornell Hospitality Quarterly, 51(4), 483-491. https://doi.org/10.1177/1938965510378574

Sinclair, S., \& Rockwell, G. (2015). Text Analysis and Visualization: Making meaning count. In: S. Schreibman, R. Siemens \& J. Unsworth (Eds.), $A$ New Companion to Digital Humanities (pp. 274290). Malden, MA: Wiley Blackwell.

Sugiyono. (2012). Metode Penelitian Bisnis. Bandung: Alfabeta.

TripAdvisor. (2017). Tentang TripAdvisor. Retrieved from https://tripadvisor.mediaroom.com/IDabout-us

Walker, L. (Eds.). (2017). Tourism and Hospitality Management. New York: Library Press.

Xu, X. (2018). Does traveler satisfaction differ in various travel group compositions?. International Journal of Contemporary Hospitality Management, 30(3), 1663-1685. https://doi.org/10.1108/ IJCHM-03-2017-0171

Zhou, L., Ye, S., Pearce, P. L., \& Wu, M. Y. (2014). Refreshing hotel satisfaction studies by reconfiguring customer review data. International Journal of Hospitality Management, 38, 1-10. https://doi.org/10.1016/j.ijhm.2013.12.004 